\title{
An Investigation into Perceptions of Facebook-use in Higher Education
}

\author{
Lasse Ellefsen ${ }^{1}$, M.A. (ORCID ID: 0000-0002-3021-518X) \\ ${ }^{1}$ Postgraduate researcher, The Media School, Bournemouth University, Bournemouth, United Kingdom \\ Correspondence: Lasse Ellefsen, Refsnesbakken 2A, 1518 Moss, Norway. E-mail: ellefsenlasse@ gmail.com
}

Received: November 10, 2015

Accepted: December 17, 2015 Online Published: December 18, 2015

doi:10.5430/ijhe.v5n1p160

URL: http://dx.doi.org/10.5430/ijhe.v5n1p160

\begin{abstract}
This paper reports the complete process for and findings resulting from an individual-led research project entitled $A n$ Investigation into Perceptions of Facebook-use in Higher Education. The aim of the research project was primarily to investigate current perceptions of using Facebook as a means for interaction between students and lecturers at university level. Findings are based on data collected from two sample populations (students and lecturers) using qualitative research methodology. Tentative findings suggest that students in particular find using Facebook for this purpose to be most appealing and would embrace such initiative in the future, whereas lecturers seem split in opinion on the matter, which is in line with previous research on social media use in higher education.
\end{abstract}

Keywords: Social media, Facebook, Higher Education, Student-teacher interaction, Student experience

\section{Introduction}

In the current Web 2.0 era, social media (SM) has become immensely popular, especially among younger people, including the student demographic that tend to use SM on a regular and very frequent basis. Facebook is today by far the most widely used SM application among not only people of all ages, but more specifically among students who seem to prefer Facebook over competing platforms as their primary social media, although they rarely remain entirely "Facebook-exclusive" as they also often use other SM platforms (McDermott 2014; Selwyn 2009). Recent statistics detail that Facebook had close to 1.5BN active users in March 2015 (Statista 2015), and research has previously reported that as much as $95 \%$ of students have Facebook accounts and use these actively.

Given the current status of social media, it is conceivable that universities, or teachers/lecturers at universities would contemplate using social media to communicate or engage with students somehow, especially since it has also been argued that a significant portion of university staff also use Facebook quite regularly and as such are not necessarily foreign to SM platforms. It has however been argued that even though a large number of university staff also use Facebook regularly, students are generally more positive than staff to the idea of using Facebook within a higher education context (Robyler, McDaniel, Webb, Herman and Witty, 2010), but that teachers are becoming increasingly more aware of social media and its inherent possibilities for various applications. Selwyn (2012) argued regarding use of social media in higher education that

“... growing numbers of educationalists are beginning to consider the possible significance and likely implications of social media for education practice and provision-especially in terms of higher education." (Selwyn, 2012, p. 2).

In light of the fact that social media is indeed something which is most often used for personal activity rather than academic/professional activity by both students and staff at universities, it seems worthwhile to investigate social media use in this context if it is used for other purposes than personal ones, especially given that there is much research which suggest that it could be beneficial to utilize Facebook in higher education. This project aims to research the current perspective of Facebook use in higher education by both students and teachers/lecturers. The aim in this project is not in any way to measure or quantify any patterns in Facebook use, but rather to investigate what the two different populations (students and teachers) think of such an application for Facebook. With this it is hoped to shed light on a matter which may contribute to enhancing the experience for students undertaking studies at university level. It is believed that this piece of research will be of interest to educators in general, but particularly to those working at university level. In addition, researchers or anyone else with an interest in contemporary social media trends and use might find this piece of research to be of interest. 


\section{Literature Review}

Social media (SM) is by no means a new phenomenon in 2015 , but there are none the less many aspects and uses of SM which might be considered as new or emerging, and as such there is much recent research into various related topics, such as perceptions of SM by different demographics, varying usage patterns and its many potential applications. Here, a review will be given of some selected relevant recent research into purposeful social media use in the context of higher education, as arguably this could be classified as a relatively new area for social media use.

Of great relevance to the current project is a recent piece of research by Dickie and Meier (2015), which reported findings from a study concerning if and how the use of Facebook in a higher education context can be of benefit. Specifically, what were reported on were findings from the use of Facebook groups as a form of additional learning and teaching support. A Facebook group offers a private environment on Facebook (although a group could also be made public and accessible for everyone), which allows group members to interact in this particular forum in several ways, such as by sharing information, materials and generally communicating within this dedicated space. If used in higher education, a group could have only students as members or both students and staff. Dickie and Meier (2015) stated that most higher education institutions and their educators today seem hesitant to communicate on social media for other purposes than promotion/advertising and therefore prefer to maintain having e-mail as the official (and consequently also main) communication channel between students and a given university. At the same time the authors noted that students use e-mail much less in recent times as SM has gained a significant foothold. Social media offers several alternative communication channels which it seems students often primarily rely on, and as such Dickie and Meier (2015) argued for the usefulness of utilizing SM in higher education and that Facebook indeed should have its place in classrooms. Prominently, the authors reported that

"The evidence presented reinforces the view that such networks have untapped potential capable of making a significant contribution to the learning and teaching process.” (Dickie and Meier, 2015, p. 1).

The authors argued that by using a Facebook group to communicate with students and for students to also interact with each other, students and teachers essentially become better part of the same community of practice as the Facebook group enables this, and results from the study pointed towards very significant student satisfaction with using Facebook in this way connected to their studies. This makes it reasonable for the current research project to investigate the perceptions of Facebook groups among the two designated populations (students and teachers).

Agozzino (2012) shared Dickie and Meier's view and argued that Facebook, as the most commonly used social media platform (among both students and others), can bring several positive elements if used in higher education. Agozzino's research was carried out in light of Uses and Gratification Theory (Agozzino, 2012, pp. 46-47), which theorizes that an audience will be liable to use media for their own gratification, and for which the premise in this specific context implied that students use the medium of Facebook in academic settings for their own gratification as they desire different information related to their studies. Agozzino (2012) used surveys to research the view of Facebook-use among undergraduate students at a university in the U.S., and findings points to several positive aspects of using Facebook in connection with education. Agozzino (2012) detailed that Facebook enabled easier communication between students and teachers, as the majority of students reportedly use Facebook significantly more than e-mail. Further, Facebook enabled the student sample to better keep up with materials relevant to their program of study, and the most important reason for why students in the sample would use Facebook for this purpose was to obtain information relevant to their studies, in line with the premise of Uses and Gratification Theory.

One consideration to keep in mind in relation to this specific point is that if Facebook is used exclusively for study-related information, some students might miss out on this unless it is clearly stated that Facebook is the main/official information channel, something which also Dickie and Meier (2015) considered as a potential problem.

Sarapin and Morris (2015) discussed the view of teachers/lecturers about Facebook use in higher education, a project which was also based on Uses and Gratification Theory. In light of this theory Sarapin and Morris (2015) argued that the main motivation for teachers when they engage with students on Facebook is achieving a better relationship with their students through more credibility and relatability, again resulting in a teacher being considered as more approachable by students. The authors stated that

"All in all, our findings supported the assumptions of uses and gratifications theory in that those instructors who communicated socially most often with their students on Facebook were those who had expected satisfaction of their needs for using the medium in this way." (Sarapin and Morris, 2015, p. 21).

According to the researchers, those teachers who interact with students in some way through social media are more likely to experience more student engagement inside and outside of classrooms as relationships are improved, and 
they will often achieve better post-course evaluations from students. Still, the teachers seem to remain as professional in the eyes of students. Sarapin and Morris (2015) mentioned as a major limitation that they had not researched teachers' perceptions of privacy concerns, despite discussing teachers' differences in self-disclosure on Facebook, which is worth keeping in mind the possibility of investigating in the current research as well.

Another piece of research to be mentioned in this literature review is by Kivunja (2015), which discussed the potential benefits resulting from social media use in higher education. Kivunja (2015) argued that social media, which has been much researched for various applications, still has yet to be fully employed in higher education, but that it holds several benefits if it is. Suggested benefits form utilizing social media such as Facebook included better student relationships developing as a result of more direct and indirect interaction (again in reference to Community of Practice Theory), high resulting student participation rates and subsequently ways of improving students' learning. Kivunja (2015) argued that social media use in higher education has still to be more widely used, but that the potential benefits suggests that it is worthwhile to utilize this.

More research has also stated the potential benefits owing to social media use in the context of higher education but also education in general, e.g. Graham (2014) which in support and addition to previous research also stated that utilizing social media will often result in students participating more and engaging more. Lam (2014) has also commented on the potential benefits of utilizing social media within higher education for a variety of purposes, including improved discussion, interaction and social relationships, and so one can observe that much research points towards both satisfaction and benefits resulting from using social media within higher education, and possibly also in education on lower levels.

Privacy is an element which is central when considering using Facebook in an educational context, since it will likely (but must not) lead to students and teachers interacting in non-traditional ways, and using social media in an educational context might cause concerns regarding various things related to a teacher-student relationship (formality, privacy etc.).

Previous research has argued that innovative technology use might be intimidating for both students and teachers. Those who wish to maintain a stricter (and more "classic") teacher-student role might find social media challenging as it requires interaction in unusual ways (Aydin, 2014; Dickie and Meier, 2015; Selwyn, 2012). As social media is still not widely used in higher education many students might consequently consider it to not be as appropriate as more official channels for contact and/or information. Considering the teacher's perspective, research has also shown that teachers can find it challenging or even intimidating to interact with students through in more informal ways on social media (Agozzino, 2012). This could owe to the fact that students often have more knowledge of social media than their course instructors.

Facebook may well be used for other things than information in connection to education as well. Amador and Amador (2014) researched how Facebook could be used for academic advising, and found that some students also seem to want to use Facebook for this. Amador and Amador (2014) argued that students seem to wish to seek advice from teachers via Facebook, but not exclusively. Findings from the study suggested that students may wish to connect with teachers on Facebook to receive some advice related to their studies, but that it is not desirable for all advice to be given through this channel. Seemingly students would wish to speak directly with teachers when it comes to guidance and advice concerning more important issues, something which may point to students still considering Facebook as less appropriate for the more serious issues connected to education.

Selwyn $(2009 ; 2012)$ has looked at how students use social media in connection to their higher education context, and argued strongly for that Facebook has vast potential for use in education, especially higher education. It was argued by Selwyn (2012) that students in contemporary society are vastly different than students of the past by being innately "digital", relying increasingly more on technology both for personal matters and also matters related to their studies. In relation to this Selwyn discussed a notion of "connectivism", a notion which means that students of today are so deeply connected to social media that they tend to display completely different learning patterns than previous generations. The argument made by Selwyn (2012) is that students now more than ever before learn by accessing information through social media on an "as needed" basis, and this was considered in relation to an old argument of any person inherently possessing two kinds of knowledge; actual knowledge gained from learning, and secondly, knowledge of where information about something can be found and accessed when needed. Given this, Selwyn (2012) sets out that students today rely so heavily on social media that it would be a mistake to not capitalize on this trend by engaging with students on social media platforms, primarily Facebook.

Draskovic, Caic and Kustrak (2013) has previously researched use of social media within Croatian higher education, and findings from their study indicate that social media-use (particularly Facebook) in this context was 
generally desirable by both populations, although students seemed more interested than teachers in this. The authors stated that it is often that case that teachers find social media to be inappropriate for use in educational contexts, so that they would rather avoid it in favor of e-mail. Except for e-mail, teachers would often wish to rely on a university's own platform for interaction, such as Blackboard, Fronter or WebCT the authors stated. Such platforms which are controlled by directly by a university then have more credibility for use within higher education among higher education staff.

Robyler et al. (2010) also researched use of Facebook in a higher education context, with data gathered from students and staff at a U.S. university. The authors stated that "faculty members have a track record of prohibiting classroom uses of technologies that are frequently used by students" (Robyler et al., 2010, p. 134), and set out the question of whether this may be detrimental for students' learning and experience, especially in a web 2.0 age. Furthermore, the authors also stated that observers have more recently witnessed changing patterns in the use of things like social media by universities and university staff, which was key for their research outset. The researchers investigated students' and staff's different patterns of using Facebook and e-mail, and found differences. Notably, Robyler et al. (2010) stated that students seem much more willing to adopt new/modern technology than staff (modern then being social media rather than e-mail in this case), in line with other research illustrating differences by students and staff in embracing social media.

Yoo and Huang (2011) researched cultural differences in adoption of different web 2.0 applications by comparing western and eastern students' use patterns. This study investigated the acceptance and use of several different web 2.0 applications, including social media (Facebook), and found that students generally seem to have a significant high rate of acceptance and use, but also reported cultural differences related to this. Relevant for the current study, Yoo and Huang (2011) found that western (American) students seem to find it easier than eastern (Korean) to interact with their peers through Facebook and using this in relation to learning. The eastern students in the study's sample showed more significantly more anxiety about interacting in a social community such as Facebook, although the eastern students otherwise showed to be more accepting than western students of other web 2.0 applications such as blogs and social virtual communities (Second Life). The researchers sought to explain this by eastern vs. western differences in individualism/collectivism, power distance and uncertainty avoidance.

Other research has among others things shown how using social media may positively influence and stimulate interaction between students and teachers, e.g. Ha and Shin (2014) and Schroeder (2013), and as such be most beneficial to try and utilize for such purposes. Schroeder (2013) also argued that there may be some controversy around the issue of teachers interacting with students in relatively new and unconventional arenas, although maintaining that this should not be a controversy as within reason teachers like everyone else should practice free speech in a contemporary and digitalizing society.

Also Wang, Scown, Urquhart and Hardman (2012) have previously investigated the benefits of using social media, Facebook in particular, within higher education. Wang et al. (2012) argued among other things for the benefits of utilizing Facebook in particular as it is so widely used (which was back in 2012 - even more widely used now a few years later) and that it has potential as an educational tool.

Said and Tahir (2013) also researched Facebook use in higher education, although in light of distance learning students. Said and Tahir argued then for a more holistic learning process potentially being achieved if Facebook is used for several reasons, and stated that interaction in such forums may be fundamental and vital. Obviously, in consideration of research on community of practice resulting from Facebook in higher education, it is understandable how Said and Tahir argues for Facebook offering positive effects.

Aydin (2014) investigated how learners of students (of English as a foreign language) interact with their teachers on Facebook. This paper reported among other things that having a Facebook environment (such as Facebook groups) stimulates interaction and in this sense is beneficial. Furthermore, Aydin argued that as interaction takes place in such an informal setting, students will more easily be willing to interact with their teachers otherwise, which can be especially beneficial in situations with less than desirable interaction, and that witnessing teachers being active on Facebook will more easily lead to students daring to participate and interact with said teachers, both on and "off" Facebook.

Donlan (2014) has also researched students' views on Facebook-use in higher education. She reported that students in higher education are apt to participating in Facebook environments in relation to learning, not all students are willing to use Facebook in this way and that there is room to research this further, which it can be added can be of great importance given that much previous research seems to point towards an overall student satisfaction with using Facebook in connection to studies somehow. Obviously, if students wish to maintain social media as something for 
use in their personal domain and would feel uncomfortable with being expected to use it in relation to education it would not be worthwhile enforcing this.

\section{Research Methodology}

This research has its foundation in an interpretist worldview, and is qualitative in nature. Qualitative research has long had a reputation of being of relatively lesser worth than quantitative research, however opinions on this seem to have shifted somewhat and the use of qualitative methods has increased over time as the value of this has been given more voice (Daymon and Holloway, 2001). While a more traditional quantitative methodology is great for collecting data in the form of numbers, so as to possibly create statistics of some sort in order to dismiss or accept a hypothesis, this sort of methodology was not deemed appropriate for the current project since this was far from the mission here. Particularly, a reason is because this research project was primarily exploratory in nature. Qualitative research methodology is therefore the more natural choice, based on arguments that such methodology is well suited to investigate how someone constructs and makes sense of their reality based on critical thinking and understanding rather than observation of quantifiable data (Woods, 2006). Given this, this research project was inherently inductive (rather than deductive) in nature.

What was primarily sought in this project was an understanding of students' and lecturers' thoughts around using the social media platform Facebook within a higher education context. The intent was not to measure a potential use of Facebook or any actual effectiveness as such, rather the goal was to gain an understanding of perceptions of Facebook-use in a higher education context, as previous related research made this seem like a worthwhile pursuit. Primarily, the following research questions had been formulated:

- RQ1: Is it desirable for students and lecturers to use Facebook in a higher education context?

- RQ2: Why is or why is it not desirable to use Facebook in higher education?

- RQ3: If Facebook use is desirable in a higher education context, in what way(s)?

- RQ4: Could privacy issues arise from social media use in higher education?

To research this, two different qualitative research tools was employed for the data collection process; focus groups with students to gain an understanding of students' view, and individual interviews with teachers/lecturers to investigate this populations' view. The sampling method utilized was non-probability convenience sampling (Daymon and Holloway, 2001), meaning that all participants were to be recruited on a convenience basis rather than randomly. Participants from both populations were recruited based on availability at the time of the data collection during a three week period. Further, both populations was recruited from the same UK university where the researcher was a registered postgraduate student (at the time of data collection), hence it was believed that the researcher should have sufficient access to these populations so as to collect the necessary primary data for the research. The decision of recruiting participants in this manner meant that it was not necessary to make contact with a gatekeeper for initial access to either of the two participant populations. Open coding was performed by the researcher for both the focus groups and individual interviews.

A consequence of the sampling method employed is that findings are not necessarily further generalizable outside of the current context (which in this case would be the one UK university from which participants were recruited), but then again generalization is more often the aim in quantitative than qualitative research, and the focus here was meant to be exploratory.

It was a requirement that all participants had to be 18 years or older and also able to give informed consent in order to participate in the study. Further, for obvious reasons it was a requirement that any person who would participate in the study had to know what Facebook is and either currently have or have previously had a Facebook account. Besides this there were no special criteria participants had to fulfill in order to qualify, although as stated recruitment was made from available persons at the university campus in question at the time of the data collection process.

Focus groups are commonly employed in social science research because of the advantages they offer (Dilshad and Latif, 2013; Sagoe, 2012), and was deemed to be suitable for this project. A focus group is a form of casual group interview, which allows a researcher to converse with a group of people in a natural way, and in doing so gather useful, and even unforeseen, data. This qualitative research technique differs from the typical interview by being more superficial in the sense that it is inherently not as deep and personal as an interview, and as such is unlikely to be the best means of extracting deeply personal thoughts from participants, and is therefore used for different purposes than interviews, much because of the benefits offered instead. To participants, a focus group may seem more natural and favorable than an individual interview (Casey and Krueger, 2000) as it is does not create a 
one-on-situation between a participant and the researcher who are present, and as such a more natural group conversation is environment is created. The conversationalists may be influenced by others' opinions like in the real world (for better and worse), engaging in more typical forms of communication (Dilshad and Latif, 2013). In comparison with this an interview may be seen as artificial by a participant. Furthermore, participants in focus groups might be prone to revealing thoughts if they witness others do the same, as long as these are not particularly sensitive in nature (Daymon and Holloway, 2001). The topic(s) to be discussed in the focus groups (perceptions of Facebook-use in higher education) in this case is not believed to be of such nature that individual interviews would instead be warranted. It is also possible that participants might recollect particular things which they would not have if they were not in a group setting where they can also listen to other participants speak.

The choice of using focus groups for data collection was also deemed appropriate by being more resource- and time efficient than individual interviews, allowing for collection of data from multiple participants at the same time. A focus group is typically made up by 6-8 participants; as such an approximate number of participants ensure that the composed group is neither too big nor to small (Daymon and Holloway, 2001; Sagoe, 2012). A too small focus group could limit the effectiveness and lead to less useful/interesting information surfacing, while too large a focus group could potentially lead to a negative situation where participants might feel it threatening to speak in front of a crowd, as well as not all participants getting an equal chance to speak.

The number of focus groups required for a research project has also been discussed in previous research. Sagoe (2012) argued that more research is needed regarding this aspect, but also argued for a reasonable number of focus groups needing to be arranged for a given project. Too few focus groups could be insufficient, while too many focus groups is time and research demanding, and a scenario with too many groups focused around the same topic might also lead to a situation where new information is simply not discovered (i.e. a topic saturation). In this project it was endeavored to recruit participants for a total of six focus groups, each consisting of six people, with an effort also made to have an equal representation of the sexes in all focus groups. Given participants' consent, audio would be recorded with an audio recorder for the duration of a group session, so that transcriptions could be made at a later time.

For the second part of the data collection process, face-to-face individual interviews were conducted with lecturers from the same university. The aim was to complete $4-8$ individual interviews, and while the final number of interviews to be made was not high, what was deemed important was to interview both teachers/lecturers who had used Facebook for academic purposes and who had not. Based on the aim to interview both teachers/lecturers who had and who had not used Facebook for academic purposes, it was not possible to set out a qualification criteria in regards to these being Facebook users or not other than for the one segment (those with past experience).

An interview guide was prepared, and the interviews were planned to have a semi-structured form, which would allow for wider discussion than a fully structured interview, while at the same time ensuring that desired topics would be discussed (Daymon and Holloway, 2001). This was the target for the research, but considering that university lecturers might not be able to spare enough time for such interviews, a backup plan was to conduct asynchronous e-mail interviews with the same participant population if necessary. This flexible form of interview has been widely and successfully employed in research in recent years, given that e-mail is now commonly accessible in many parts of the world (Ratislavova and Ratislav, 2014). It is flexible in the sense that an interview which could otherwise not have been conducted because of time restraints or difficulties with organizing a meeting between a researcher and participant can actually be conducted. A researcher can utilize an interview guide and e-mail questions to the participant(s), which the participant(s) may subsequently consider when time allows. All questions may be e-mailed at the same time, or over time through several e-mails. A more open interview structure could also be achieved if general topics rather than questions for consideration were sent to the participant, so that the participant could give his/her opinion on topics instead of answering questions.

\section{Findings and Discussion}

The findings from this project shall now be presented, and a discussion of findings will be incorporated into this section. The reason for the fusion of these two parts is that since there are no qualitative data to present and analyze before discussing these, it seems logical to present these in the same section. The tentative findings presented here are based on data collected from both focus groups and individual interviews, albeit only four of each. Admittedly, the relative low final number of focus groups and interviews in this study is less than ideal, but much data was still gathered. The focus groups were made up of participants from several different countries (China, Germany, Norway, the U.K., the U.S. and Vietnam). It was not on the agenda in this particular project to investigate possible differences 
in perceptions owing to nationality or culture, although that would potentially have been rewarding in its own right (and could be recommended for future research).

Although it was endeavored to have an approximately equal number of male and female participants in the focus groups, males were ultimately underrepresented in all but one. As regards the individual interviewees, three out of four were male. Something which was deemed important in relation to the interview part of the data collection process was to interview as many lecturers that had not previously used Facebook somehow in relation to their teaching as those who had, something which led to fewer total interviews than ideally desirable seeing as there were more potential participants available for interviews who had no such experience with Facebook.

\subsection{The Student Sample's Perceptions}

First of all, in all of the focus groups the participants were without exception positive to the notion of potentially utilizing Facebook within higher education. All of the students that participated in this study considered themselves as regular users of Facebook, although not all had as of yet used Facebook in connection with their higher education studies. The minority who had not yet used Facebook for such purposes were open and positive to trying it in the future and would not mind it as long as it did not require much extra effort on their part. When asked, extra effort included things such as having to create another social media account for which they would have to remember another set of login data, using a social media platform which did not have a sophisticated application for mobile phone use, and especially something which they would need to spend significant time learning the inner and outer workings of. It was argued by several participants that Facebook is already so embedded in the daily lives of many students that it is particularly easy for this demographic to get used to using this social media platform for something related to higher education. An argument made was that since most students are already familiar with how Facebook works it seems a much better option than if any other social media platform(s) were to be used instead. It would therefore be argued that the set out research question concerning desirability of SM use in higher education (RQ1) could be answered with "yes" as far as regards students' perceptions.

One participant stated to habitually checking Facebook almost immediately after waking up every morning, as well as it being one of last things which he would do before going to sleep at night (an admittance which was immediately received with laughter as well as confirming nods by the other present participants in that focus group). Another female participant said she would not rush to check Facebook in the morning after waking up unless she had received several notifications, but that she would regularly catch up on recent events on Facebook during breakfast.

When asked directly, participants gave varying answers as to exactly how often they would be prone to checking Facebook throughout a typical day, ranging from a few times to a few times per hour. Given that all of the participants would in fact at least use Facebook regularly every day, it makes it reasonable to assume that information distributed in this forum by a university or lecturer would be likely to be seen by students within a reasonable time. Admittedly there are likely differences in perceptions of what exactly constitutes "within reasonable time", although for instance the time frame 24 hours should fit for the named purpose. Previous research has shown that students in general check their university e-mail (which is the official channel for information between a university and students and consequently the information channel which universities use regularly and most often) much more rarely than they do their own private e-mail and social media. A Facebook group works so that it is can give its members notifications when there is activity in the group, and a group member will then virtually instantly receive a notification in his or her Facebook app. Depending on a person's individual pattern for using Facebook, the notification can be instantly received on several devices, such as a laptop, tablet or smart/mobile phone.

One female participant who had previously been, and was currently, part of a Facebook group for her study program stated that she would usually check her smartphone almost immediately as soon as she received a notification because she felt the suspense of an unchecked notification to be almost unbearable. In light of this, it could be argued that a student, especially one with such a Facebook usage pattern, would likely then read new information shared in a study program's Facebook group much faster than he or she would if the information/materials were distributed via e-mail, especially university e-mail. Other participants stated that using Facebook in this way in relation to their study program was desirable because it would allow them to not only interact with their peers and as such experience better relationships (sense of community of practice), but also because it would just make it easier and less time consuming for them to keep up with what is going on with their study program. In relation to RQ2 these things would answer the questions of why it would be desirable to use Facebook for this purpose.

With little exception, the participants primarily stated to consider Facebook as their main social media choice. Main in this case meant that Facebook is the social media platform which they would spend the most time using on a normal day. In addition, all of the participants stated to have one or more other social media accounts which they 
would use to a varying degree; some said to use other social media almost as much as Facebook while others stated to much more rarely use other platforms. Several participants stated that it is the norm for young people to have several different social media accounts regardless of whether these would be used (in addition to Facebook) sparingly or constantly. These stated social media usage patterns were the same between sexes and nationalities with one exception; participants from China stated that they had had little or no experience with Facebook prior to coming to the UK, and as such had other social media platforms ranked as primary. The reason given was that Facebook is blocked in China and is therefore not readily accessible without using a VPN (virtual private network), and consequently it is used by very few people there. However, two Chinese participants said that they had indeed used Facebook while in China as well, owing to use of a VPN service, and while in the UK all of the Chinese participants stated to currently using Facebook regularly as well as their other primary social media.

There are several ways in which it was suggested that Facebook could be used within higher education, but tentatively in relation to answering RQ3 in this project, it specifically comes across that having a Facebook group for interaction connected to a study program is what is most desirable for students (or at least for the participants in the current study, so as not to generalize without a proper quantitative foundation). A constructed Facebook Page or use of Facebook Messenger was also mentioned; however it is the use of Facebook groups which as previously stated seems most desirable. A Facebook Page was generally considered as being too static and unsuitable for interaction, as it does not facilitate two-way communication and sense of community in the same way as a group. Facebook Messenger was considered as better to use than a page, but not quite as good as a group.

There was some disagreement in opinion over whether having a Facebook group connected to a study program should exclude any other options. An argument made was that even though a Facebook group would provide a suitable environment for certain things, some things would be better suited in the type of private environment that Facebook's messenger service provides. Use of Facebook Messenger was then not desirable as a replacement for a group, but as an alternative for private matters or matters of delicate nature. It is important to mention here that the participants who suggested using Facebook Messenger (in addition) for the named purposes would wish to rather physically go and talk to a teacher face-to-face for such matters, but that if a teacher was unavailable for a longer period of time or if the matter was urgent then the Facebook's Messenger service would be a desirable option.

None of the students would disapprove of being members of a Facebook group for academic purposes, although some argued that they might not find it overly useful, depending on the activity in the group by both teachers and students. Those most optimistic were those who had previously used Facebook in relation to their studies and as such had first-hand experience. It was mentioned that a Facebook group could be used well by teachers for things such as distribution of PowerPoint slides from lectures, information regarding room changes or timetable changes, as well as any other relevant information which could be posted in the same way. There were some who did not feel that a Facebook group would be of much use, who argued that the same materials and information could be shared in a university's online learning portal or via e-mail. Conversely, all participants were in agreement about regularly checking Facebook significantly more often than either of the two suggested alternatives for distributing the same information and materials. Considering this, it would be more likely that a student would come across information of greater contemporary importance quicker if it is distributed via Facebook rather than the stated alternatives. Some participants also said that they currently enjoyed being members of a group which also served another purpose than ones strictly related to their program of study; namely as a social place where students and teachers can post invitations to meet for various events outside of the classroom, which again is something which contributes to an increased feeling of membership in a community of practice both inside and outside of the classroom. This is in line with previous research around precisely Community of Practice resulting from social media use (e.g. Dickie and Meier, 2015) as well as User Gratification Theory research (e.g. Agozzino, 2012).

Those in favor of having a Facebook group for their program of study would all prefer if this was set up and run by a teacher or member of staff, as opposed to a student, regardless of the guidelines for use. The reason given was that it would then in fact be official in nature. Interestingly, this view by the student participants concerning a Facebook group possibly being of official nature contrasted sharply with the teachers' perception of this (see section 4.2). Obviously, such a group could be started by anyone, and that anyone would then have administrative rights within that group, which is consequently something participants argued for is why it would be most suitable with teacher control over such a group. A student (even a student representative) with a grudge to another student might potentially remove posts or comments from that student, but it was not believed by the participants that a teacher or any other member of academic staff would be liable to do such a thing. Several participants expressed a wish for a teacher they know to have the responsibility for moderating what goes on in a Facebook group, so that they would feel a sense of security in the same way as in a classroom where a teacher functions as a leader. 
Related to the previous point, the topic of guidelines or rules for behavior in such an "official" Facebook group was discussed with great interest by the participants in all of the focus groups. It was argued by many that Facebook is usually a place where they would feel free to express themselves more or less as they desire, but that they would not feel comfortable expressing themselves as freely in such a Facebook group due to its more official nature. One participant said that she would hesitate to write something in such a forum at all if she was unsure about the correctness or appropriateness of her language. Another participant said that he would always want to double and triple check his spelling whenever he knew that his teachers would see what he wrote, but that he would not hesitate to write/post something as long as he was certain that his spelling was indeed correct.

The participants mostly agreed on that any such group (being then seemingly official in nature) should have some rules for behavior, but that these rules should be unwritten rules just like in a classroom. No one would post or condone posting of bad language or verbal abuse of a student or teacher, inappropriate materials (of racist, pornographic or discriminating nature), even though such materials would not technically be illegal. Further, some felt that it would be acceptable to share jokes and similar things in such a Facebook group while others felt that even that would be inappropriate, and that such a Facebook group (or rather, its contents) should be kept as serious (academic) as possible. This was perhaps the point which triggered the most debate among the participants in the different focus groups. One participant stated that she would appreciate if a teacher would start using the group first and post whatever he or she thinks is appropriate, so that students could understand what is appropriate and not, whereas another said she would not be afraid to post a joke or funny picture to spread good atmosphere regardless of whether anyone had done something similar before. There did not seem to be a significant difference in perception among males and females regarding this, nor between people from different nationalities.

Finally in considering RQ4, there was some disagreement among the participants concerning privacy issues arising from them being in the same Facebook group as teachers, which makes them and their Facebook profile more visible to teachers. Facebook is a social media application designed for personal use, and there might therefore be issues regarding privacy to consider when and if students are expected to use it in relation to studies in higher education. Some participants were worried that teachers might become aware of their spare time activity on Facebook as it manifests in circulated pictures and comments, and stated that they would take steps to make ensure that their profile is not publicly available so that that teachers would not be able to observe such. However, the same participants stated that this is something they would wish to keep control of in any case as they would not want potential employers to be able to see such activity either, and so this was not directly a privacy concern arising from using Facebook groups in relation to their studies. Many stated that they believed teachers to not want to investigate their spare time activity, but that if they for some reason would wish this it would be possible to some extent regardless of whether they were members of the same Facebook group. Similarly, several participants expressed that if they really wanted to they could see some personal information about teachers on Facebook, but that they would not normally be interested in this, regardless of whether a teacher's profile was publicly visible or private.

\subsection{The Teacher/Lecturer Sample's Perceptions}

The lecturer sample consisted of lecturers who had hands-on experience with utilizing Facebook in the context of higher education in some way, as well as lecturers who had only used Facebook privately and not otherwise.

The lecturers who had previously used Facebook in relation to their teaching had primarily experience with a Facebook group for this, but had also used Facebook Messenger to a lesser degree. Communication via Facebook Messenger was seen as a worse solution than interaction with students in a group, as it is comes across as much less formal than regular e-mail (and especially university run e-mail), at the same time as it may be viewed differently by students. One lecturer argued that he liked to use Facebook in order to share or communicate with the whole student body, not individual students as he would rather use face-to-face meeting or e-mail for that. For this reason the lecturer would not like to use Facebook messenger in communicating with students, although it could serve a purpose if there was ever a need for quick communication about less important matters with a single student.

In relation to considering RQ3, these Facebook-experienced lecturers expressed satisfaction with having a Facebook group (or several) in which they could interact with their students and considered this the best way of using Facebook for this purpose. Importantly, and in relation to answering the research questions for this project, the lecturers stated that it would be a loss, in lack of other words, to not be able to go on interacting with students in a Facebook group if they were to ever quit utilizing Facebook in this way. In agreement with Selwyn (2012), their perception was that it would be a mistake to not try and utilize, or capitalize, on students' social media use if possible, as interaction between students and between students and teachers is most positive and desirable. 
The lecturers had primarily shared information related to relevant study programs in a such Facebook group, as well as links to interesting articles on the internet that were somehow related to their students' study programs. One lecturer had in addition also given out information about social events, something he found to be acceptable to do in such a Facebook group, and something which he believed students had appreciated. The lecturers with such Facebook experience were under the impression that things shared in a group had been noticed and read by students much faster than if the same had been distributed via e-mail, especially via the university's e-mail which all suspected that students do not check as often as they should. Furthermore, it was mentioned that at times, a post in such a group could even stimulate further and wider interaction and discussion between students outside and the group and inside a classroom. This aspect regarding student engagement resulting from social media (Facebook) has been previously argued for in various research, e.g. by Graham (2014), Kivunja (2015), Lam (2014) and Sarapin and Morris (2015).

A significant difference in perception concerning the status of a Facebook group was evident between the student and lecturer sample. Whereas the students felt that a Facebook group, if organized and used by teachers, would in fact be official in nature, the lecturers perceived any such group as more of a side project which they could use for less important (but highly relevant) things. Information regarding room- or timetable changes were mentioned as precisely the type of information which was most suitable for sharing in a group rather than via e-mail, as most students would receive a notification about it immediately on their phones, and could then also spread the information to any students that were not part of the Facebook group or did not have the Facebook application on their mobile phone and so missed out on the instant notification. The lecturers stated that in any case a Facebook group would never be official for them or a university because of the fact that ultimately Facebook has complete control over its contents and could for instance one day decide to shut down all Facebook groups with short (or no) notice, and in doing so create problems if too much rested on the group functionality. That being said, they would feel as comfortable with sharing course related information in a Facebook group as via university e-mail, but they would not however like to use a Facebook group for sharing materials such as lecture slides. This they felt to be better shared in a university's dedicated virtual space where students log on and download what they need as they need.

In line with research on User Gratification Theory, (e.g. Agozzino, 2012), it could be argued that the interviewed lecturers in the sample used Facebook for their own gratification, whether to achieve easier communication with students, create better interaction or otherwise. As far as the stated research questions for this project go, it has been shown that some lecturers find it desirable to use Facebook within higher education, and especially the group functionality offered by Facebook. This is also an answer to RQ 2, concerning why it is desirable to use SM (for those it applies to).

In relation to the stated research questions again (is FB desirable, why/why not), the lecturers who had not used Facebook in relation to their teaching questioned the appropriateness, owing to several factors such as the inherent informality associated with Facebook, privacy concerns and uncertainty regarding the functionality of Facebook groups in particular. Privacy was not given as a main issue though, and so in relation to RQ4 it does not seem that privacy issues were of great concern for the teacher/lecturer sample. These lecturers all felt that communication with students is best suitable via official channels (university e-mail or a university's student portal) or face-to-face meetings, either inside or outside of the classroom. They expressed a concern that it may come to the point where students unreasonably naturally expect to be able to interact with universities and teachers through Facebook, although universities and individual teachers may not want this. For this reason they would advise students against relying too much on unofficial channels for communication or interaction, and bear in mind that formality in communication and interaction is an integrated part of the university system, and that in this regard universities are also training students in preparation for their later careers in which they will need to observe rules and regulations around formality and professionalism.

In line with previous research (e.g. Dickie and Meier, 2015; Robyler et al. 2010; Selwyn, 2009; Selwyn 2012), some university staff are shown to be hesitant to using social media (for academic purposes), while students are as expected significantly more open to this.

Furthermore, one lecturer who had not used Facebook also expressed that since Facebook is a privately owned company's product and not a university's, the confidentiality of anything shared or said in such a forum may not be guaranteed, and he would therefore rather always wish to use a university's own virtual learning platform for the same purpose, which arguably is possible through the built in functionality of such university run-platforms. However, the lecturer did foresee that any university-run virtual learning platform would likely never become as 
popular in use among students as for instance Facebook, and as such previous attempts as encouraging students to interact (with their peers and/or teachers) had not been significantly successful, and similarly it would likely not be an overly successful attempt to try and interact with students through such a platform if the same could be done through Facebook given that it is as popular as it is among students.

The lecturers who had not used Facebook for interaction with students previously all stated a concern over whether using for instance a Facebook group could exclude some students. This based on the fact that it is not possible to know for certain whether all students are Facebook users, and neither is it possible (or desirable) to try and force students to use Facebook to interact with their teachers or classmates. This expressed concern about inclusion and exclusion is then something which had led them to question the use of Facebook. With that said, as well as the previous points, these lecturers were indeed open to possibility of using Facebook (groups) in the future, given more consideration. This is an interesting find in lights of previous research which has shown university staff to often be hesitant to using social media. Considering the set out research questions for this project, it could be argued that it is partly desirable - based on individual lecturers - desirable to use Facebook in this way.

\section{Problems Encountered}

A series of focus groups and individual interviews were conducted in order to gather primary data for the current research project. From the outset, the target was to arrange six focus groups and conduct 4-8 individual interviews, and ultimately this ambition proved to be partly unreachable due to difficulties with recruiting the desired number of participants. A major reason for the experienced difficulties with recruitment was that the three-week period set aside for data collection was set in the month of July, a month with relatively fewer people present on university campuses in the UK due to undergraduate courses having finished for the academic year, while at the same time being a period in which many postgraduate students go away for summer holidays. To remedy this it would have been more suitable if data collection had been carried out in a part of the academic year when more students are likely to be present on campuses.

29 students were originally recruited for the focus groups; however 8 decided to withdraw at too late a time to be replaced. The remaining 21 participants were then used in four focus groups. Although it was not possible to recruit as many participants as desired it is still believed that valuable data was collected from the four arranged focus groups. Audio was recorded only during three out of the four focus groups, as not all of the participants were comfortable with this.

With the aim being 4-8 individual interviews, it could be claimed that this was almost satisfactory reached as 4 was the end result. Each interview lasted between 30-45 minutes, and audio was recorded of each. The reason for the fewer number of interviews achieved was that it was desirable to maintain a balance in the number of interviewees that had and that did not have previous experience with using Facebook in relation to their teaching or a study program.

\section{Perceived Limitations of the Research}

As with all research, also with this there are some perceived limitations which shall be stated for the research to be as transparent as possible. First of all, because of the qualitative rather than quantitative approach one cannot generalize the findings, such as the exceedingly positive perception of Facebook use in higher education by students as well as lecturers with experience of this. If the research had been constructed with quantitative methodology then, obviously depending on the sample size, one could likely have been able to generalize the findings. Strictly speaking, as it is the reported findings are not generalizable outside of the context of the student- and lecturer community at one particular university in the UK. It would have been interesting to see others conduct a "fresh" quantitative methodology based follow-up study around the same topic, as Facebook use in academia seems to be exceedingly well perceived at least among the participants in the current study.

Further, one should keep it mind that neither of the samples were balanced in terms of gender, so there may be more differences in perceptions among males and females than what came across in the current study. A suggestion is then that any follow-up study should try to work to ensure a balanced sample in this regard, something which would obviously be very important if a quantitative study were to be carried out so that generalization could be made. Also, it could be of interest to investigate differences in perceptions of social media use in an educational context based on differences in nationality and/or culture.

Finally, if the methodology was not aimed at investigating the perceptions of two distinct groups of people and a wider or differently focused literature review was carried out, the focus of the research would have changed. E.g. more focus could have been on only lecturers' perceptions, or that of students and more resources could have been 
dedicated to either. Arguably it was interesting to discover the perceptions of both sides, as it were, but a focus on only one side would have allowed for more in depth understanding of that particular segment. Furthermore, as it is, it could seem (although an exhaustive count has not been made) that more research on social media use in educational contexts has been quantitative rather than qualitative, and so it would be suggested to carry out more qualitative (explorative rather than quantifying) research on this.

\section{Conclusion}

The aim of this project was to investigate students' and teachers' contemporary perceptions of using Facebook in a higher education context, and several interesting, although tentative, findings has been reported. Students were seemingly entirely positive to using Facebook, and leaned especially towards Facebook groups, as long as it would not require much extra effort from them. The students who had previously been members in Facebook groups for their study programs argued that it had made for a better total experience for their study program by incorporating them into a community with their peers as well as their teachers, and stated that they would miss using Facebook in this manner in the future if they were to stop.

Lecturers were split in the perception of using Facebook within academia, owing to various reasons. While lecturers who had no past experience with using Facebook in an educational context did not wish to try it immediately, they were open to learning more about it from colleagues and perhaps trying it in the future if it was considered to potentially enhance students' learning experience as well be of use (one could here then consider User Gratification Theory). While concerns for privacy had not been a major reason for not using Facebook in this manner, concern for the appropriateness and effectiveness had been. On the other side, the lecturers who had experience with using Facebook groups for a study program were very satisfied with this, and similarly to the students they stated that they would have missed using Facebook in this way if they were to ever stop, both owing to their personal sense of it being positive and because of the satisfaction from students resulting from it. These lecturers argued that Facebook groups had allowed them to interact with students in a classroom-related arena outside of the normal classroom, both for strictly study related things and for more casual things, and in this way possibly enhanced students' learning experience.

\section{Acknowledgements}

Many thanks are expressed to all students and lecturers at Bournemouth University that participated in either focus groups or interviews for the current study. You know who you are! :)

\section{References}

Agozzino, A. (2012). Capitalizing on Social Media: Recommendations for Using Facebook in the Classroom. Ubiquitous Learning: An International Journal [online], 5 (3), 43-52.

Amador, J. \& Amador, P. (2014). Academic Advising via Facebook: Examining Student Help Seeking. Internet and Higher Education [online], 21, 9-16. http://dx.doi.org/10.1016/j.iheduc.2013.10.003

Aydin, S. (2014). Foreign Language Learners' Interactions with their Teachers on Facebook. System [online], 42, 155-163. http://dx.doi.org/10.1016/j.system.2013.12.001

Casey, M.A. \& Krueger, R.A. (2000). Focus Groups: A Practical Guide for Applied Research. 3rd ed. Thousand Oaks, CA: Sage.

Daymon, C. \& Holloway, I. (2011). Qualitative Research Methods in Public Relations and Marketing Communications. $2^{\text {nd }}$ ed. London: Routledge.

Dickie, V.A. \& Meyer, H. (2015). The Facebook Tutor: Networking Education. Ubiquitous Learning: An International Journal [online], 8 (2), 1-12.

Dilshad, R.M. \& Latif, M.I. (2013). Focus Group Interview as a Tool for Qualitative Research: An Analysis. Pakistan Journal of Social Sciences [online], 33 (1), 191-198.

Donlan, L. (2014). Exploring the Views of Students on the Use of Facebook in University Teaching and Learning. Journal of Further \& Higher Education [online], 38 (4), 572-588. http://dx.doi.org/10.1080/0309877X.2012.726973

Draskovic, N., Caic, M., \& Kustrak, A. (2013). Croatian perspective(s) on the Lecturer-Student Interaction Through Social Media. International Journal of Management Cases [online], 15 (4), 331-340.

Graham, M. (2014). Social Media as a Tool for Increased Student Participation and Engagement outside the Classroom in Higher Education. Journal of Perspectives in Applied Academic Practice [online], 2 (3), 16-24. 
Ha, J. \& Shin, D.H. (2014). Facebook in a Standard College Class: An Alternative Conduit for Promoting Student Teacher Interaction. American Communication Journal [online], 16 (1), 36-52.

Kivunja, C. (2015). Innovative Methodologies for $21^{\text {st }}$ Century Learning, Teaching and Assessment: A Convenience Sampling Investigation Into the Use of Social Media Technologies in Higher Education. International Journal of Higher Education [online], 4 (2), 1-26.

Lam, L. (2014). An Innovative Research on the Usage of Facebook in the Higher Education Context of Hong Kong. Electronic Journal of e-Learning [online], 10 (4), 378-386.

McDermott, J., 2014. Facebook Losing its Edge among College-aged Adults. Digiday [online], 21 January 2014. Available from: http://digiday.com/platforms/social-platforms-college-kids-now-prefer/ [Accessed 1 June 2015].

Ratislavova, K. and Ratislav, J. (2014). Asynchronous Email Interview as a Qualitative Research Method in the Humanities. Human Affairs [online], 24, 452-460. http://dx.doi.org/ 10.2478/s13374-014-0240-y

Roblyer, M.D., McDaniel, M., Webb, M., Herman, J. \& Witty, J.V. (2010). Findings on Facebook in Higher Education: A Comparison of College Faculty and Student Uses and Perceptions of Social Networking Sites. Internet and Higher Education [online], 13 (3), 134-140. http://dx.doi.org/10.1016/j.iheduc.2010.03.002

Sagoe, D. (2012). Precincts and Prospects of Using Focus Groups in Social and Behavioral Science Research. The Qualitative Report [online], 17, 1-16.

Said, M.N.H.M. \& Tahir, L.M. (2013). Towards Identification of Students' Holistic Learning Process Through Facebook in Higher Education. Procedia - Social and Behavioral Sciences [online], 97, 307-313. http://dx.doi.org/ 10.1016/j.sbspro.2013.10.238

Sarapin, S.H. \& Morris, P.L. (2015). Faculty and Facebook Friending: Instructor-student Online Social Communication from the Professor's Perspective. Internet and Higher Education [online], 27, 14-23. http://dx.doi.org/ 10.1016/j.iheduc.2015.04.001

Schroeder, M. (2013). Keeping the Free in Teacher Speech Rights: Protecting Teachers and Their Use of Social Media to Communicate with Students Beyond the Schoolhouse Gates. Richmond Journal of Law and Technology [online], 19 (2).

Selwyn, S. (2009). Faceworking: Exploring Students' Education-related use of Facebook. Learning, Media and Technology [online], 34 (2), 157-174. http://dx.doi.org/ 10.1080/17439880902923622

Selwyn, S. (2012). Social Media in Higher Education. Education Arena [online]. Available from: http://www.educationarena.com/pdf/sample/sample-essay-selwyn.pdf [Accessed 5 June 2015].

Statista, 2015. Number of Monthly Active Facebook Users as of $1^{\text {st }}$ quarter 2015 (in millions). Statista [online], 2015. Available

from: http://www.statista.com/statistics/264810/number-of-monthly-active-facebook-users-worldwide/ [Accessed 1 June 2015].

Wang, R., Scown, P., Urquhart, C. \& Hardman, J. (2014). Tapping the Educational Potential of Facebook. Education and Information Technologies [online], 19 (1), 21-39. http://dx.doi.org/10.1007/s10639-012-9206-z

Woods, P. (2006). Qualitative research. University of Plymouth [online]. Available from: http://www.edu.plymouth.ac.uk/resined/qualitative\%20methods\%202/qualrshm.htm [Accessed 15 June 2015].

Yoo, S.J. \& Huang, W.-H.D. (2011). Comparison of Web 2.0 Technology Acceptance level Based on Cultural Differences. Educational Technology \& Society [online], 14 (4), 241-252. 